\title{
Necrobiosis Lipoidica: A case report with dermoscopic review
}

\author{
Sameer Shrestha ${ }^{1}$, Natalia Spierings ${ }^{2}$, and Suchana Marahatta ${ }^{1}$ \\ ${ }^{1}$ BP Koirala Institute of Health Sciences \\ ${ }^{2}$ Affiliation not available
}

October 16, 2020

\begin{abstract}
We are presenting a case of Necrobiosis Lipodica disease in a 55 year lady whose diabetes status was not known at the time of presentation in dermatology OPD. Traditionally, the diagnosis is confirmed by histopathological examination (HPE). Dermoscopy can also be used as a noninvasive tool to confirm the diagnosis.
\end{abstract}

Keywords: Dermoscopy, Necrobiosis Lipoidica, Diabetes mellitus, Granulomatous Skin Condition

\section{Key Clinical Message}

The diagnosis of NL is made traditionally by Histopathology. This case report with review helps to diagnosis NL via dermoscopy and differentiating it from other granulomatous skin condition.

\section{Introduction}

Necrobiosis Lipoidica (NL) is a rare idiopathic, chronic granulomatous skin condition that usually presents as asymptomatic erythematous papule on legs progressing to waxy plaques that may develop atrophy and ulceration (1). It can complicate Diabetes mellitus (DM) in about $0.3 \%$ (2). Dermoscopy may be a useful non-invasive tool to differentiate NL from other granulomatous skin conditions like lupus Vulgaris (LV), cutaneous Leishmaniasis(CL), granuloma annular(GA) and cutaneous Sarcoidosis(CS). However little is known about the characteristic findings of NL on dermoscopy. We present a case of NL that was confirmed by HPE along with its dermoscopic features and a review of the literature.

\section{Case Report}

A 55-year old lady presented with a 3 year history of two asymptomatic erythematous lesions, one on each shin, which had started as pinhead size papules. There was no history of any trauma, DM or thyroid disorders. The papule on the right leg gradually increased in size over three years forming a 5 by 4 centimetre waxy erythematous irregularly shaped plaque ( Fig. 1 a) with a well-defined erythematous margin. The center of the plaque comprised telangiectatic vessels with yellow-hued area of atrophy. The surrounding skin was normal. There was no increase in temperature or tenderness on palpating the lesion. The papule on left shin increased in size over the same period forming a similar waxy erythematous round to oval 5 by 2 centimetre plaque ( Fig. 1 b), also with a well-defined erythematous margin and normal surrounding skin. On examination at presentation, another $1.5 \mathrm{~cm}$ diameter plaque was found $2 \mathrm{~cm}$ medial to the initial lesion on her left shin.

Dermoscopic examination (Dermlite DL4 with non-polarising filter) revealed linear vessels with branches distributed uniformly on the background of a yellow structureless area. White linear streaks was also visible (Fig2) . 
Based on the clinical macroscopic and dermoscopic examination, a provisional diagnosis of NL was made. Blood investigation showed Fasting Blood Sugar of $210 \mathrm{mg} / \mathrm{dl}$, Post prandial of $300 \mathrm{mg} / \mathrm{dl}$, HbA1c 7.3 and thyroid function test was normal. HPE revealed an epidermis with basket weave hyperkeratosis and irregular acanthosis. There was presence of granulomatous inflammatory infiltrate throughout the dermis surrounding the degenerated collagen. The inflammatory infiltrate comprised of epithelioid histiocytes, lymphocytes, plasma cell and Langerhans's type giant cell. Stain for Acid fast bacilli was negative. The clinical and histological findings confirmed the diagnosis of NL (Fig. 3).

The patient was treated with potent topical steroids to apply once daily to the lesions and referred to the internal medicine team for management of newly diagnosed DM.

\section{Discussion}

NL is associated with DM, sarcoidosis, thyroid disorders, inflammatory bowel disorder and in healthy individuals (3). The association of NL with DM varies from $11 \%$ to $87 \%$ (4)(5). Various theories regarding the pathogenesis of the condition have been suggested. For example, in DM, microangiopathy due to deposition of glycosylated protein may be the cause of the NL. Others have considered hypoxia as the cause of the NL.(6)

NL presents as painless well-defined discrete erythematous papules or small plaques or nodules usually on the leg that later coalesce forming larger waxy, erythematous to yellowish plaque. The center of plaque may show area of atrophy and telangiectasia. Later the lesion may develop ulceration in around $30 \%$ of cases and Squamous cell carcinoma in rare cases.(4)

HPE done in our case showed degeneration of collagen throughout the dermis with palisading granulomas comprising predominantly of lymphocytes and histiocytes that confirmed the diagnosis. The absence of dermal mucin deposition differentiates it from GA. $(6,7)$

Histopathology is must for diagnosis of NL. Dermoscopy can also be used as a noninvasive tool to confirm the diagnosis. A few case series and reports highlighted on diagnosing and differentiating NL dermoscopically from other granulomatous skin conditions as highlighted in tables 1 and 2 .

Hence from this report we would like to highlight that: progression of vessel morphology from linear curved (comma-shaped) to linear serpentine to linear with branches(arborizing vessels) with progession of the disease, that are distributed uniformly on structureless yellow-white background are important clue on dermoscopy for diagnosing NL. In classical arborizing pattern of BCC, the vessels ramify into finest capillaries. The arborizing vessels in NL are almost equal in diameters without ramification into finest capillaries and presence of multiple anastomosing ramifications.

\section{Author Contribution}

Name of authors Nature of work

1. Dr. Samir Shrestha. Concept, Design, record collection, manuscript writing

2. Dr. Natalia MK Spierings Manuscript editing, guidance

3. Suchana Marahatta Manuscript editing, guidance \& final approval

\section{Conflict of Interest: None}

\section{Acknowledgement}

It has been a great privilege and huge learning experience to conduct this study. I would like to take this opportunity to express my gratitude to all the co-authors for their contributions and encouragement.

I also express my sincere thanks to my colleague Dr. Raksha Pathak for her constant encouragement and moral support in completion of this manuscript.

\section{Reference:}


1. Kota S, Kota S, Modi K, Jammula S, Meher L. Necrobiosis lipoidica diabeticorum: A case-based review of literature. Indian J Endocrinol Metab. 2012;16(4):614.

2. Investigation P. Lipoidica. 2015;

3. Reid SD, Ladizinski B, Lee K, Baibergenova A, Alavi A. Update on necrobiosis lipoidica: A review of etiology, diagnosis, and treatment options. J Am Acad Dermatol [Internet]. 2013;69(5):783-91. Available from: http://dx.doi.org/10.1016/j.jaad.2013.05.034

4. Smith JG, Annulare G. Lipoidica. 2015;17-22.

5. O’Toole EA, Kennedy U, Nolan JJ, Young MM, Rogers S, Barnes L. Necrobiosis lipoidica: Only a minority of patients have diabetes mellitus. Br J Dermatol. 1999;140(2):283-6.

6. Tong LX, Penn L, Meehan SA, Kim RH. Necrobiosis lipoidica. Dermatol Online J. 2018;24(12):6-9.

7. Shulstad R. Granuloma annulare. Adv NPs PAs. 2013;4(11):21-2.

8. Vásquez-López, F. Kreusch, J. Marghoob J. Clinical and Laboratory Investigations Dermoscopic semiology: further insights into vascular features by screening a large spectrum of nontumoral skin lesions. 2004;226-31.

9. Zalaudek I, Kreusch J, Giacomel J, Ferrara G, Catrical C, Argenziano G. How to diagnose nonpigmented skin tumors: A review of vascular structures seen with dermoscopy: Part I. Melanocytic skin tumors. J Am Acad Dermatol. 2010;63(3):361-74.

10. Lallas A, Giacomel J, Argenziano G, García-García B, González-Fernández D, Zalaudek I, et al. Dermoscopy in general dermatology: Practical tips for the clinician. Br J Dermatol. 2014;170(3):514-26.

11. Brasiello M, Zalaudek I, Ferrara G, Gourhant JY, Capoluongo P, Roma P, et al. Lupus vulgaris: A new look at an old symptom - The lupoma observed with dermoscopy. Dermatology. 2009;218(2):172-4.

12. Dermoscopic features of cutaneous leishmaniasis: Study of 52 lesions. J Am Acad Dermatol. 2017;76(6):AB97.

13. Pellicano R, Tiodorovic-Zivkovic D, Gourhant JY, Catricalà C, Ferrara G, Caldarola G, et al. Dermoscopy of cutaneous sarcoidosis. Dermatology. 2010;221(1):51-4.

\section{Figures}

[ Fig. 1(a) and (b) showing the waxy erythematous plaques on bilateral shin of the patient,

Fig. 2 showing dermoscopic appearance of the lesion (arrow showing linear vessels with branches distributed uniformly, ${ }^{*}$ white linear streaks, ${ }^{* *}$ yellow structureless area) and

Fig. 3 showing the granulomatous inflammatory infiltrate throughout the dermis surrounding the degenerated collagen. The inflammatory infiltrate comprised of epithelioid histiocytes, lymphocytes, plasma cell and Langerhans's type giant cell(shown in inlet within the figure)]

Tables

[Table 1. Dermoscopy findings of NL ${ }^{(8,9),(10)}$ ]

[Table 2. Differentiating Dermoscopy findings of NL from other granulomatous conditions (9)(11)(12)(13) ]

\section{Hosted file}

4. Figures-converted.pdf available at https://authorea.com/users/367704/articles/487034necrobiosis-lipoidica-a-case-report-with-dermoscopic-review 